\title{
Investigating the Relationship between Organizational Climate and Service Performance: The Role of Work Passion and Leader-Member Exchange
}

\author{
Anthony Frank Obeng ${ }^{1}$, Patricia Eshun ${ }^{2}$ \\ ${ }^{1}$ School of Management, Jiangsu University, Zhenjiang, 212013, China, \\ ${ }^{1}$ E-mail: 5103181239@stmail.ujs.edu.cn (Corresponding author) \\ ${ }^{2}$ Credit Department, Lower-Pra Rural Bank, Shama, 00233, Ghana, ${ }^{2}$ E-mail: eshunpat2000@yahoo.com
}

\begin{abstract}
This study aimed at examining the effect of organizational climate (Instrumental aspect of climate, Cognitive aspect of climate, and Emotional aspect of climate) on the service performance of employees of the hospitality industry in five regions of Ghana. 418 matched responses were received and used to test the hypotheses. Confirmatory factor analysis revealed that the data had a good model fit. Hierarchical multiple regression was employed to analyze the data. Findings of the survey revealed that the instrumental aspect of climate, cognitive aspect of climate, and emotional aspect of climate had a positive and significant effect on both work passion and service performance. Work passion partially mediated the relationship between the instrumental aspect of climate and service performance and the relationship between the cognitive aspect of climate and service performance. However, only the relationship between the cognitive aspect of climate and work passion was moderated by the leader-member exchange. Implications and recommendations for future studies are discussed.

Key words Instrumental-Cognitive-Emotional, Leader-Member Exchange, Organizational Climate, Service Performance, Work Passion

Received: 17 May $2020 \quad$ (C) The Authors 2020

Revised: 20 Jun 2020 Published by Human Resource Management Academic Research Society (www.hrmars.com)

Accepted: $\quad 30$ Jun 2020 This article is published under the Creative Commons Attribution (CC BY 4.0) license. Anyone may Published Online: $12 \mathrm{Jul} 2020$ reproduce, distribute, translate and create derivative works of this article (for both commercial and non-commercial purposes), subject to full attribution to the original publication and authors. The full terms of this license may be seen at: $\mathrm{http} / / /$ creativecommons.org/licences/by/4.0/legalcode
\end{abstract}

\section{Introduction}

From a theoretical point of view, the thorough conceptualization of an organization by its employees denotes organizational climate (OC) That encapsulates the decision-making process and shares the meaning of employees' organizational environment (Schneider et al., 2017). However, Rivai et al. (2019) opine that the $O C$ is the awareness of the organization's members and those who keep in contact with the company on what happens daily in the world or internally. This affects the employees' attitudes and behaviors, and the performance of organizational leaders that decide the organization's success. Instrumental, cognitive, and emotional climate as dimensions of OC promotes optimistic attitudes of employees to the work as they consider the organization's equal treatment (Huang et al., 2019). The climate in an organization depends on workers because organizations offer their customers services with intensive human resources (Ölçer \& Florescu, 2015), hence, employee service performance (SP) very crucial. 
Experiencing the right workplace climate makes employees relate well with each other, promoting SP. Therefore, SP considered in this study as a dependent variable indicates a direct connection to positive organizational efficiency, showing financial or non-financial results (Saleem et al., 2019). However, behaviors do not only yield SP but have implications known to be the source of physical and mental behaviors that vary from the outcomes (Tweedie et al., 2019). Consequently, this makes work passion (WP) as an employee's inherent behavior towards his/her performance very paramount in this context. Though SP is attainable with a favorable OC (Asril et al., 2019), it is also imperative to assess employees' behavior and attitude which mostly influence the passion towards work. Usually, WP is considered as a strong inclination towards an activity that people like and find important (Schulte-Holthaus, 2019; Vallerand et al., 2003). Also, relationships between managers and subordinates are paramount when it comes to OC and SP nexus. For over three decades, managers and subordinate relationships have seen the light of detailed studies (Buch et al., 2019). However, Martin et al. (2016) confirmed some valuable outcomes attributable to engaging in high-quality leader-member exchange (LMX). Lately, LMX has been addressed as the inimitable relationship-grounded by social exchange among supervisors and subordinates (Graen \& UhlBien, 1995). Moreover, $L M X$ is a concept that started as a substitute for regular leadership types (Graen \& Uhl-Bien, 1995). The theory of social exchange explains how two or more parties come to exchange resources, how successions of exchanges take place, and how exchanges affect the relationship between the involved parties (Cropanzano et al., 2017). The social exchange theory (SET) is used to underpin the relationships in this study since there is an exchange and reciprocity norm relationship among the used variables. SET stresses that relationships gradually evolve into trust, loyalty, and commitments needed if those interests are subject to explicit 'rules' of exchange (Cropanzano \& Mitchell, 2005).

Recently, management activities such as leadership, workplace climate, and behaviors towards SP in the hospitality companies in Ghana have however weakened. This has led to underperformance since it has downplayed the incentive of the employees. Studies that sought to investigate these challenges have overlooked the mitigating effect of LMX and the mediating mechanism of WP for which this present study seeks to address this gap in the extant literature. Owing to this, the current study thus seeks to investigate: (i) the effects of the dimensions of OC on SP; (ii) whether WP can mediate the relationship between OC dimensions and SP; and (iii) whether LMX can moderate the relationship between OC dimensions and WP.

\section{Literature and Hypotheses Development}

\subsection{Organizational Climate and Service Performance}

Ali et al. (2018) defined organizational climate (OC) as a shared perception of what the organization is like in terms of practices, policies, procedures, routines, and rewards and expected behaviors found within organizational units. According to Chu \& Chiu (2017), the following are ascribed as OC dimensions; (1) Instrumental aspect: deals with the procedural way by which a task is to be completed, including extra reward. (2) Cognitive aspect: is the psychological involvement of an individual in the activities of the work to be performed. (3) Emotional aspect: depicts the social interpersonal relations that exist between an individual and others, such as cooperation, participation, and warmth \& friendliness. It is noted that SP is a positive contribution to the organization's efficiency, which can be assessed by employees through various mechanisms (Mensah et al., 2019; Saleem et al., 2019). Ekawati \& Tjahjono (2019) postulated that an organization's climate is the human environment in which the workers of the organization do their work. Signifying that, essentially, all employees want a pleasant climate in carrying out their work. Creating an enabling environment for individuals will encourage the creation of a conducive work environment that will instill SP for both customers and the organization. Also, Qiu et al. (2015) were of the view that OC does not represent stress on the organizational environment and the members' reasoning and attitudes. However, the outcome of employees' perception of the work environment on work motivation and SP has an additional impact on organizational performance. Universally, most scholars in this area of study found that the $\mathrm{OC}$ has a positive impact on the SP of employees. Thus, it is proposed that;

H1: Organizational climate will significantly predict service performance.

H1a: there is a significant relationship between the instrumental aspect of climate and service performance. 
H1b: there is a significant relationship between the cognitive aspect of climate and service performance.

H1c: there is a significant relationship between the emotional aspect of climate and service performance

\subsection{Mediating Role of Work Passion}

Several scholars and reformers have elucidated OC diversely. Seemly, there is harmony on what constitutes OC. For instance, Litwin \& Stringer (1968) as opined by Randhawa \& Kaur (2015) assessed OC as "a set of measurable properties of the work environment, perceived directly or indirectly by the people who live and work in this environment and assumed to influence their motivation and behavior." Empirically, most studies have found it rarely linking WP to OC and SP relationship. However, for organizational well-being and SP level to be achieved, it is required that WP becomes crucial in addressing OC. According to Vallerand et al. (2003) as opined by Gaan \& Mohanty (2019) that passion is of two kinds i.e. harmonious passion which involves the independent and voluntary internalization in which the employee is spontaneously aligned to the job due to its importance but not social status or recognition and an obsessive passion which is viewed to be a forced internalization of the work, implying that employees observe their jobs as significant due to some social status outcomes devoted to the job. Moreover, the employee becomes obsessive when the job dictates the employee's emotions, which sometimes affects the other aspects of life in the form of career conflict. Hence, we proposed that:

H2: Organizational climate will significantly influence employee work passion.

H2a: There is a significant relationship between the instrumental aspect of climate and work passion

$\mathrm{H} 2 \mathrm{~b}$ : There is a significant relationship between the cognitive aspect of climate and work passion

$\mathrm{H} 2 \mathrm{c}$ : There is a significant relationship between the emotional aspect of climate and work passion

It has been very imperative to examine the relationship between WP and SP (Ahmed et al., 2016) as well as $\mathrm{OC}$, of which contemporary researchers have delved into finding answers to the relationship. Burke et al. (2015) cross-cultural study in Russia and China found that harmonious and obsessive WP has an association with performance. These recent studies are a forward step in the utilization of passion in the organizational environment. Although researchers agree that both types of WP (harmonious and obsessive) may indeed affect SP, the notion that harmonious passion leads to solely positive outcomes, whereas obsessive passion as vice versa has not found consistent empirical support. However, though positive harmonious passion has an association with performance (Ahmed et al., 2016; Suarez et al., 2015), other studies view both as positive predictors of performance (Bonneville-Roussy et al., 2011; Ericsson et al., 1993). We, therefore, hypothesize that;

$\mathrm{H} 3$ : Work passion will play a mediating role in the relationship between organizational climate and service performance.

H3a: Work passion will mediate the relationship between an instrumental aspect of climate and service performance.

$\mathrm{H} 3 \mathrm{~b}$ : Work passion will mediate the relationship between the cognitive aspect of climate and service performance.

$\mathrm{H} 3 \mathrm{c}$ : Work passion will mediate the relationship between the emotional aspect of climate and service performance.

\subsection{The Moderating Role of Leader-Member Exchange (LMX)}

Theoretically, social exchange theory has been the backbone for elucidating the LMX theory foundation (Bernerth et al., 2007; Dulebohn et al., 2012; Matta \& Van Dyne, 2015). The theory of LMX leads us to go beyond cognitive explanations to also consider how the exchange relationship context may impact an employee's SP. Applying LMX increases work output and job satisfaction. Kuvaas \& Buch (2018), posit that if a certain degree of interaction between managers and subordinates is warranted for WP, it is by applying the LMX. Further, to positively contribute to organizational level goals and objectives, LMX relationships have to be associated with higher levels of employees' WP. Empirically most studies have found it rarely linking LMX to WP. Moreover, the social exchange theory directs employees to go further in cognitive explanations and also to consider how the exchange relationship perspective influences an 
employee's WP. Besides, Martin et al. (2016) posit that employees' behavior is strongly influenced by the supportiveness of leaders, and stresses that leaders develop unique relationships with each of their followers and that the quality of this relationship affects followers' work attitudes and behavior. This portrays that the linkage that exists within the manager and the subordinate is governed by both concepts. Hence, we hypothesize that:

H4: LMX will play a moderating role in the relationship between organizational climate and work passion.

H4a: LMX will moderate the relationship between the instrumental aspect of climate and Work passion.

H4b: LMX will moderate the relationship between the cognitive aspect of climate and Work passion. H4c: LMX will moderate the relationship between the emotional aspect of climate and Work passion.

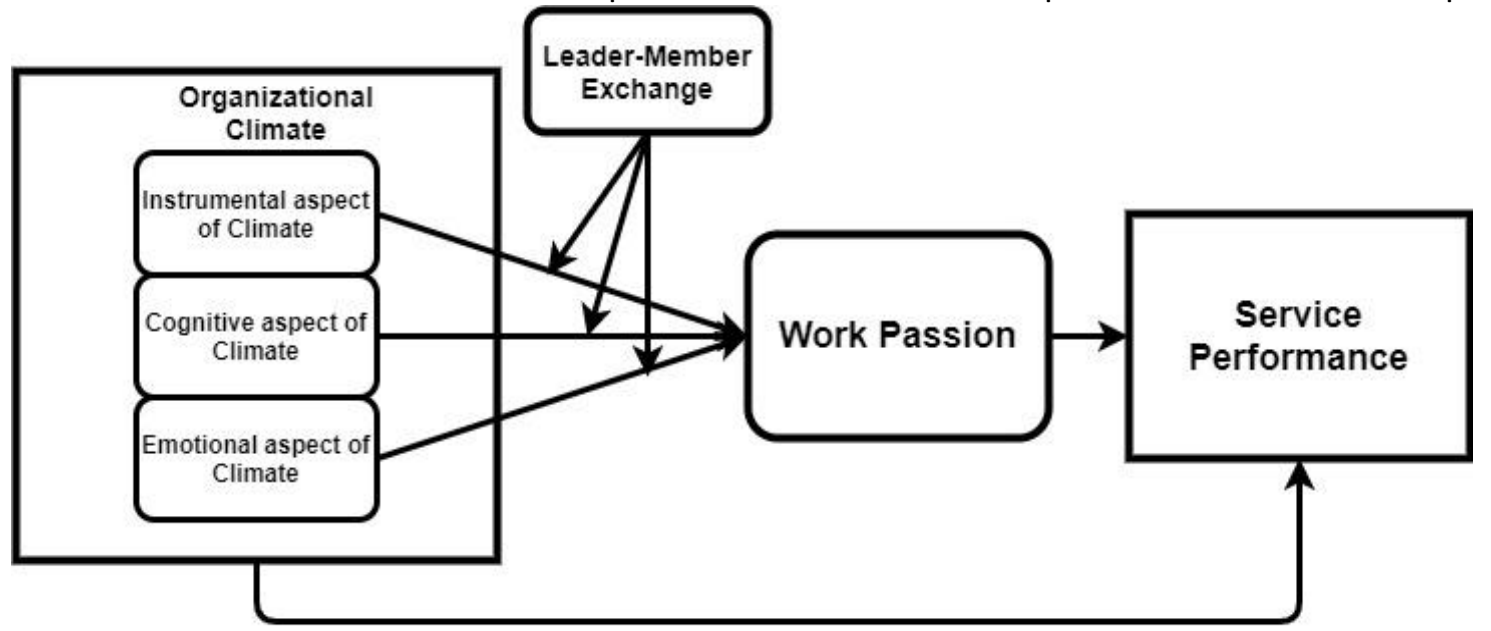

Figure 1. Conceptualized model

\section{Methodology of research}

\subsection{Sample and Procedure}

This present study examines the relationship between OC and SP as perceived by workers in the hospitality industry in Ghana. Letters were sent to the hotels and restaurant companies in 5 regions namely; Greater Accra, Ashanti, Western, Eastern, Central region of Ghana requesting their participation in the study. These regions were selected base on purposive sampling i.e. due to the number of hotels and restaurants located in these regions. Out of 38 companies, 35 granted our request making 3520 employees with each branch of the company having approximately 20 employees. An appointment was booked and meetings held with the participants and it was agreed that questionnaires would be given to the employees containing questions on employee's attitudes and behaviors towards their services to customers. Respondents were assured of confidentiality and some reward (pen and dairy) for recognition of participation. A selection condition was prepared to be followed in choosing employees across the 5 regions of Ghana. Employees were selected base on one being a worker for more than a year to guarantee that the employee is well involved in the climate of the company. The simple random sampling method was used to select representative samples from each hotel and restaurant. 605 questionnaires were then distributed using a simple random sampling technique. However, a total of 550 were retrieved with 418 as valid responses representing the sample size of this study. The data collection period was two months.

Out of 418 representing $69.1 \%$ valid responses, $220(52.6 \%)$ male with an average $1.47(\mathrm{SD}=0.50)$ and $198(47.4 \%)$ females. 28 employees were between the ages of $18-25$ representing (6.7\%), 376 were also between the ages of $26-45$ representing $90 \%$, while 14 employees were between the ages of $46-60$ representing 3.3\%. Degree qualification was 171 representing $40.9 \%$, senior high school was 244 representing $58.4 \%$, and junior high school was 3 representing $0.7 \% .103(24.6 \%)$ employees were at the receptionist, $147(35.2 \%)$ waiters/waitress, $147(35.2 \%)$ cooks, and others, $21(5 \%)$ (i.e. 13 food and beverages and 8 securities). Years of service recorded 42(10\%) employees working for 1- 4, 207 (49.5\%) for 
5-8 years, $129(30.9 \%)$ for $9-12$ years, $39(9.3 \%)$ for $13-16$, and only $1(0.2 \%)$ had worked for more than 16 years.

\subsection{Measures}

The main variables of this study are organizational climate (OC), service performance (SP), LeaderMember Exchange (LMX), and Work Passion (WP). The main dependent variable is SP. WP is a mediator in the relationship between $O C$ and SP, while LMX moderates the direct effect of OC on WP. 5 point Likertscale $(1=$ strongly disagree to $5=$ strongly agree) was used to measure all items except SP that was measured with 6 points Likert scale ranging from ( $1=$ very low to $6=$ can't say). We measured organizational climate with a three-dimensional scale namely, Instrumental aspect of climate (IAC) $(\alpha=0.92)$ adopted from the CLIOR Scale Peña Suárez, Muñiz Fernández, Campillo Álvarez, Fonseca Pedrero, and García Cueto (2013) made up of 15 items (sample "In my job, innovative contributions are appreciated"), the Cognitive aspect of climate (ICA) ( $\alpha=0.93$ ) developed by Ang et al. (2007) with 10 items (sample "I know the legal and economic systems of other cultures"), and Emotional aspect of climate (EAC) $(\alpha=0.88)$ from the emotional climate scale (ECS) developed by (Páez et al., 1997) and adopted by (Conejero \& Etxebarria, 2007) with 10 items (sample "there is a climate of trust in the institutions"). This scale has been used by authorities across various disciplines, e.g. Huang et al. (2019) study in the ecology industry, and this influenced the adoption of this scale in measuring OC. LMX ( $\alpha=0.89)$ was measured with 11 items scale (sample "I offer to do things for my boss which I am not required to do; that is, I do them as a personal favor for him or her.") from the LMX and Employee Behaviour Scale developed by (Wayne \& Green, 1993) for this study. Work passion scale was propounded by Vallerand et al. (2003) also used by Vallerand et al. (2010) in other settings of disciplines was adopted for this study. The scale has two dimensions (harmonious and obsessive) with each dimension containing 7-item. Harmonious Work Passion has a sample question as follows "This business is in harmony with the other activities in my life" while the Obsessive Work Passion sample question is "I have difficulties controlling my urge to do my business activities". The two dimensions had high internal consistency and were highly correlated having a combined Cronbach alpha of $(\alpha=0.80)$. It is usually advisable to analyze such a scale as a single score by averaging across items (Erdogan \& Enders, 2007; Lapointe et al., 2019). The authors, therefore, analyzed the WP construct as a one-dimensional scale. Service performance scale was adopted from SP index (SURVPERF) developed by Landrum et al. (2009) with 21 items in total, including 5 tangible $(\alpha=0.91)$ items (sample "there are visually appealing facilities") 5 reliability $(\alpha=0.85)$ items (sample "I perform service right the first time"), 4 responsiveness $(\alpha=0.90)$ items (sample "readiness to respond to customers request"), 4 assurance $(\alpha=0.96)$ item (sample "giving individual customer optimum attention") and 3 empathy $(\alpha=0.93)$ item (sample "Staff who understand the needs of customers").

\section{Results}

In this present study, the descriptive statistics, and the correlations of the variables used for the survey, were analyzed first. Statistical Package for Social Science (SPSS) version 23 was used to perform Exploratory Factor Analysis (EFA) to ascertain items that loaded appropriately under their respective components. The authors relied on the factor loadings of the EFA results to further check the fitness of the model by applying Confirmatory Factor Analysis (CFA) through AMOS (version 21) and the maximum likelihood method of estimation. Items deleted during the EFA process totaled 22 (24.72\%) out of 81 items and did not affect the reliability, validity, and dimensionality of the measures. Hierarchical regression analysis was employed as the main statistical technique in SPSS (version 23) to estimate the path analysis. The procedures outlined by Baron and Kenny (1986) for performing mediation-moderation analysis were also followed. All alpha values for the scales of the constructs surpass the threshold 0.7. suggested by Nunnally (1978). A normed chi-square (X2/df) of 3 or less, SRMR of 0.08 or less, root mean square error of approximation (RMSEA) of 0.08 or less, Tucker-Lewis fit index (TLI) of 0.90 or higher and comparative fit index (CFI) of 0.90 or higher will indicate a great sign of unidimensionality for the data set (Byrne, 1994; Issac et al., 2006). The CFA was performed for all the 11 factors and a good model fit was yielded i.e. Normed Chi-square $(\mathrm{X} 2 / \mathrm{df})=2.133 ; \mathrm{GFI}=.857 ; \mathrm{IFI}=0.943 ; \mathrm{TLI}=0.933 ; \mathrm{CFI}=0.942 ; \mathrm{RMSEA}=0.052$ which satisfied goodness of fit of data (Gaskin \& Lim, 2016; Joreskog \& Sorbom, 1993). 
Table 1. Confirmatory Factor Analysis of the measurement model

\begin{tabular}{cccccccc}
\hline Model & CMIN & df & RMSEA & GFI & IFI & TLI & CFI \\
\hline 1. Hypothesized 11-factor model & $1669.974^{* * *}$ & 783 & 0.052 & 0.857 & 0.943 & 0.933 & 0.942 \\
\hline
\end{tabular}

Note: ${ }^{1} \mathrm{CMIN} / \mathrm{df}=2.133$.

\subsection{Descriptive Statistics and inter-correlation}

The statistics and inter-correlations for our variables are shown in Table 2. The variables exhibited good internal consistency $(\alpha \geq .70)$. IAC $(r=0.444, p<0.05)$, CAC $(r=0.105, p<0.05), E A C(r=0.159, p<0.05), L M X$ $(r=0.306, p<0.05)$ and WP $(r=0.235, p<0.01)$ positively correlated with SP. IAC and LMX further correlated positively with WP. IAC $(r=0.410, p<0.01), C A C(r=0.104, p<0.05)$ and $E A C(r=0.142, p<0.01)$ also correlated positively with LMX. The study further showed that IAC and EAC had positive relation with each other $(r=0.302, p<0.01)$.

Table 2. Descriptive Statistics and Inter-correlation

\begin{tabular}{cccccccccccc}
\hline & Gender & Age & E.Q & Pos. & Y.S & IAC & CAC & EAC & LMX & WP & SP \\
\hline Gender & - & & & & & & & & & \\
Age & 0.025 & - & & & & & & & & \\
E.Q & $.214^{* *}$ & $-.100^{*}$ & - & & & & & & & \\
Pos. & 0.057 & 0.025 & $.259^{* *}$ & - & & & & & & \\
Y.S & 0.003 & -0.051 & -0.074 & $-.215^{* *}$ & - & & & & & \\
IAC & $-.129^{* *}$ & $-.176^{* *}$ & $.200^{* *}$ & $-.141^{* *}$ & -0.065 & - & & & & \\
CAC & -0.017 & -0.014 & 0.00 & $.108^{*}$ & $.259^{* *}$ & 0.026 & - & & & \\
EAC & $.110^{*}$ & $-.128^{* *}$ & 0.007 & -0.062 & $-.104^{*}$ & $.302^{* *}$ & 0.063 & - & & \\
LMX & $-.129^{* *}$ & $-.155^{* *}$ & 0.023 & $-.126^{* *}$ & 0.079 & $.410^{* *}$ & $.104^{*}$ & $.142^{* *}$ & - & \\
WP & -0.096 & $.195^{* *}$ & $.103^{*}$ & $.128^{* *}$ & $-.138^{* *}$ & $.327^{* *}$ & 0.055 & 0.037 & $.146^{* *}$ & - \\
SP & -0.017 & -0.003 & $.113^{*}$ & $-.167^{* *}$ & 0.004 & $.444^{* *}$ & $.105^{*}$ & $.159^{* *}$ & $.306^{* *}$ & $.235^{* *}$ & - \\
\hline
\end{tabular}

Note: $\mathrm{E} . \mathrm{Q}=$ Educational qualification; Pos=Position; $\mathrm{Y} . \mathrm{S}=$ Years of service; $\mathrm{WP}=$ work passion; $\mathrm{SP}=$ service performance; ${ }^{*} p<0.05 ;{ }^{*} p<0.01$; Alpha coefficients are reported in parentheses along the diagonal.

\subsection{Data Analysis}

The direct effect of Organizational Climate on Work Passion and Service Performance

To test the mediating effect of WP, standardized regression analysis was employed to test the generative effect of the mediation method. Baron and Kenny (1986) 3-step approach was followed. (1) The independent variable significantly predicts the dependent variable, (2) the independent variable significantly predicts the mediator, (3) when the dependent variable is regressed on both variables (the independent variable and the mediator), and the mediator significantly predicts the dependent variable while the predictive utility of the independent variable is reduced. If both the mediator and independent variables are significant in this regression, there is partial mediation. Moreover, if the mediator is significant but the independent variable is not significant in this regression, there is full mediation.

From Table 3, the results showed that the IAC had a direct positive and significant effect on SP yielding $B=0.434(t=9.239, p<0.001)$, hence $\mathrm{H} 1 \mathrm{a}$ is supported. Also, IAC again predicted WP resulting in $B=0.377(t=7.989, p<0.001)$, therefore $\mathrm{H} 2 \mathrm{a}$ is supported. However, when SP was regressed on both IAC and $W P$, standardized regression estimates for IAC $B=0.390$ with $p<0.001$ and WP $b=0.117$ with $p<0.01$ indicating a partial mediation, hence, $\mathrm{H} 3 \mathrm{a}$ is supported. Moreover, the CAC had a direct positive and significant effect on SP $(B)=0.149(t=2.992, p<0.001)$, hence $\mathrm{H} 1 \mathrm{~b}$ is supported. CAC again positively predicted WP $(B)=0.082(t=1.656, p<0.1)$, hence providing support for $\mathrm{H} 2 \mathrm{~b}$. When the SP was regressed on both CAC and WP, a standardized regression estimate for CAC $B=0.129(t=2.658, p<0.05)$ and a standardized coefficient estimate for WP $B=0.245$ ( $t=5.068, p<0.001)$ were recorded, hence, WP partially mediated the relationship, therefore, $\mathrm{H} 3 \mathrm{~b}$ is supported. Furthermore, in table 3 , the EAC also had a direct positive and significant effect on SP $B=0.157(t=3.227, p<0.05)$, hence, $\mathrm{H} 1 \mathrm{c}$ is supported. However, EAC 
could not directly predict WP $(B)=0.074(t=1.544, p>0.05)$, hence $\mathrm{H} 2 \mathrm{c}$ is not supported. Surprisingly, when $S P$ was regressed on both EAC and WP, standardized regression estimates for EAC $B=0.138$ with $p<0.01$ and WP $B=0.245$ with $p<0.001$, EAC failed to directly and statistically predict $W P$, hence $\mathrm{H} 3 \mathrm{c}$ was not supported.

Table 3. Mediating effect of Work passion on the relationship between dimensions of organizational climate and Service performance

\begin{tabular}{ccccccccc}
\hline Step & Predictors & Criterion & $\boldsymbol{R}$ & $\boldsymbol{R}^{\mathbf{2}}$ & $\boldsymbol{a} \cdot \boldsymbol{R}^{\mathbf{2}}$ & $\boldsymbol{F}$ & $\boldsymbol{B}$ & $\boldsymbol{t}$ \\
\hline 1 & IAC & SP & 0.468 & 0.219 & 0.352 & 19.213 & $0.434^{* * *}$ & 9.239 \\
2 & IAC & WP & 0.460 & 0.211 & 0.200 & 18.348 & $0.377^{* * *}$ & 7.989 \\
3 & IAC & SP & & & & & $0.390^{* * *}$ & 7.769 \\
& WP & & & & & & $0.117^{* *}$ & 2.390 \\
1 & CAC & SP & 0.277 & 0.077 & 0.063 & 5.709 & $0.149 * * *$ & 2.992 \\
2 & CAC & WP & 0.308 & 0.095 & 0.082 & 7.176 & $0.082^{*}$ & 1.656 \\
3 & CAC & SP & & & & & $0.129 * *$ & 2.658 \\
& WP & & & & & & $0.245^{* * *}$ & 5.068 \\
1 & EAC & SP & 0.283 & 0.080 & 0.067 & 5.967 & $0.157^{* *}$ & 3.227 \\
2 & EAC & WP & 0.307 & 0.094 & 0.081 & 7.110 & 0.074 & 1.544 \\
3 & EAC & SP & & & & & $0.138^{* *}$ & 2.928 \\
& WP & & & & & & $0.245^{* * *}$ & 5.074 \\
\hline
\end{tabular}

Note: a. $\mathrm{R}^{2}=$ adjusted $\mathrm{R}^{2}$; Standardized coefficient of regression $=6$; Instrumental aspect organizational climate $=I A C$; Cognitive aspect of organizational climate $=C A C$; Emotional aspect of organizational climate $=E A C$; Work Passion=WP; Service Performance=SP; ${ }^{* *}=$ Sig. at $0.001 ; * *=$ Sig. at $0.01 ; *=$ Sig. at 0.05

\section{Moderating effect of LMX on the relationship between dimensions of organizational climate and work passion}

Applying hierarchical regression analysis, the moderated relationships were estimated. The results are set out in Table, 5a, 5b, and, $5 c$. First, the findings in table $5 a$ revealed that IAC still exerted a positive and significant effect on WP, providing additional support for $\mathrm{H} 2 \mathrm{a}$. However, maintaining IAC as the independent variable, the moderating effect of $L M X$ is presented in Table $5 a$. The interaction term between $I A C$ and $L M X$ is negative and not statistically significant. Hence, no moderation effect, therefore, H4a was not supported. In Table $5 \mathrm{~b}$, it is indicated in the results that the CAC influence on WP was not statistically significant in model 2 . However, in model 3 the product interaction term between EAC and LMX was positive and statistically significant indicating there was a moderation effect on the relationship between CAC and WP. Hence, H4b was supported. Also, in Table 5c, EAC's influence on WP was not statistically significant in model 2, however, LMX had a positive and significant influence on WP in model 2. In testing for the moderation effect, the interaction term between EAC and LMX was negative and statistically not significant depicting that there was no moderation effect on the relationship between EAC and WP in model 3. Hence, $\mathrm{H} 4 \mathrm{c}$ was not supported.

Table 5a. Moderation effect of LMX on the relationship between IAC and WP

\begin{tabular}{lcccccc}
\hline & & Model1 & & & \multicolumn{2}{c}{ Model 3 } \\
WP
\end{tabular}

Note: ${ }^{*} \mathrm{p}<0.05 ; * * * \mathrm{p}<0.001$ 
Table 5b. Moderation effect of LMX on the relationship between CAC and WP

\begin{tabular}{lccccc}
\hline & & Model1 & & \multicolumn{2}{c}{ Model 2} \\
& & WP & & WP & \multicolumn{2}{c}{ Model 3 } \\
WP
\end{tabular}

Note: ${ }^{*} \mathrm{p}<0.05 ; * * \mathrm{p}<0.001$.

Table 5c. Moderation effect of LMX on the relationship between EAC and WP

\begin{tabular}{|c|c|c|c|c|c|c|c|}
\hline & \multicolumn{2}{|r|}{$\begin{array}{c}\text { Model1 } \\
\text { WP }\end{array}$} & \multicolumn{2}{|r|}{$\begin{array}{c}\text { Model } 2 \\
\text { WP }\end{array}$} & \multicolumn{3}{|c|}{$\begin{array}{c}\text { Model } 3 \\
\text { WP }\end{array}$} \\
\hline & $b_{1}$ & $t$ & $b_{2}$ & $t$ & $b_{3}$ & $t$ & $R^{2}$ \\
\hline (Constant) & & 7.250 & & 3.889 & & 2.305 & 0.125 \\
\hline Gender & $-.132 * *$ & -2.730 & $-.113 * *$ & -2.347 & $-.113^{* *}$ & -2.332 & $(0.001)$ \\
\hline Age & $.203 * * *$ & 4.281 & $.235 * * *$ & 4.949 & $.236 * * *$ & 4.972 & \\
\hline Edu.Qua & $.124^{* *}$ & 2.481 & $.112 * *$ & 2.267 & $.112^{* *}$ & 2.268 & \\
\hline Position & .077 & 1.541 & $.103^{* *}$ & 2.090 & $.106^{* *}$ & 2.143 & \\
\hline Year.service & $-.101 * *$ & -2.103 & $-.104 * *$ & -2.175 & $-.106 * *$ & -2.203 & \\
\hline EAC & & & .049 & 1.015 & .197 & 1.011 & \\
\hline LMX & & & $.180 * * *$ & 3.733 & $.269 * *$ & 2.176 & \\
\hline EAC*LMX & & & & & -.187 & -.785 & \\
\hline
\end{tabular}

Note: ${ }^{*} p<0.05 ;{ }^{* * *} p<0.001$

\section{Discussions and conclusions}

This study aimed at examining how OC dimensions (IAC, CAC, and EAC) promotes SP. The findings indicate that IAC, CAC, and EAC positively and significantly influenced SP directly. Moreover, WP partially mediated the relationship between IAC and SP. Also, WP partially mediated the relationship between CAC and SP. However, WP was not statistically significant in the relationship between EAC and SP. Furthermore, LMX was used to moderate the relationship between IAC, CAC, and EAC and SP. The main relationship of the findings supports the work of Kang et al. (2016) who indicated in their research that elements of organizational climate, job characteristics, and other antecedents of work performance may mainly influence individual behavior and performance through work passion. The outcomes of this current study also support the assertion made by Neal et al. (2000) that organizational climate directly influences performance.

The findings showed that $L M X$ significantly affected the relationship between CAC and WP, indicating the moderation effect. This happens due to the satisfactory leader-member relationship activities such as support, loyalty, and trust that projects how well employees perceive that supervisors relate cordially with them which increases their love and affection for the work they do. Undeniably, employees usually assume that supervisors are leaders of the organization who upholds the organization's aims and directs employees' actions as a reflection of the organization (Eisenberger et al., 2002), even though LMX could not have a discernible moderating effect on both IAC and EAC. CAC deals with the psychological participation of the employees in the course of the work to be done. This promotes innovative contributions by the employee and rapport between the supervisor and the employee which leads to employees being passionate about their job and having a sense of belongingness. This will strengthen the WP of the employees as influenced by LMX. Also, exhibiting a high level of independence in achieving goals limits unwarranted intervention and interference of managers. A high level of autonomy mostly reduces this 
interference and promotes LMX relationships in organizations. This improves WP since it brings about a favorable climate workplace. It is identified in previous studies that employees with more favorable attitudes had a strong positive relationship with outcome variables as compared to those with unfavorable attitudes (Cannon, Herda, \& Puffer, 2019). For example, employees' attitudes are to be assessed by their work passion towards their assigned job and role in an organization (Permarupan et al., 2013). Also, Audenaert et al. (2019) found a positive correlation between LMX and how employees perform their tasks.

\subsection{Practical Implication}

The study also has some implications for practice. Firstly, the findings indicate that only the relationship between CAC and SP was mediated by LMX. Therefore, organizations should promote LMX within the organization. Any policy that destroys the supervisor-employee relationship should not be encouraged. Secondly, when employees contribute immensely by introducing innovative ideas into the organization, they become proud and improve their passion for work. This in effect makes employees highly innovative. Organizations should map strategies to invest many resources and motivate employees to become innovative in detailing their job. Thirdly, the demographics highlight that the majority of the staff has senior high school qualification which presupposes that they lack high education. We recommend that organizations should have standardized recruitment, selection, and training program that attracts highly skilled and competent staff for their services.

\subsection{Limitations and suggestions for future studies}

As the case in similar studies, our study also has some limitations. To begin, IAC, CAC, and EAC were the only dimensions considered to examine the effect of OC on WP and SP. Other aspects of OC such as work clarity, standard, responsibilities, and opportunity for career development, to mention but a few should also be considered in future studies as they may influence SP. Again, the estimator employed for the path analysis was hierarchical regression, conversely, future studies may consider the structural equation model. The study made use of employees in responding to the questionnaire used to gather data, however, future researchers should consider the use of customers as respondents in similar studies.

\section{References}

1. Ahmed, A., Hameed, I., \& Mahmood, S. (2016). Linking passion to organizational citizenship behavior and employee performance: The mediating role of work engagement. Pakistan Journal of Commerce and Social Sciences, 10(2), 316-334.

2. Ali, M., Lei, S., \& Wei, X.-Y. (2018). The mediating role of the employee relations climate in the relationship between strategic HRM and organizational performance in Chinese banks. Journal of Innovation \& Knowledge, 3(3), 115-122.

3. Ang, S., Van Dyne, L., Koh, C., Ng, K. Y., Templer, K. J., Tay, C., \& Chandrasekar, N. A. (2007). Cultural intelligence: Its measurement and effects on cultural judgment and decision making, cultural adaptation and task performance. Management and organization review, 3(3), 335-371.

4. Asril, A., Lian, B., \& Tobari, T. (2019). The effect of organization climate and school's culture on teachers' professional performance in Palembang, Indonesia. European Journal of Education Studies.

5. Audenaert, M., Decramer, A., George, B., Verschuere, B., \& Van Waeyenberg, T. (2019). When employee performance management affects individual innovation in public organizations: The role of consistency and LMX. The International Journal of Human Resource Management, 30(5), 815-834.

6. Baron, R. M., \& Kenny, D. A. (1986). The moderator-mediator variable distinction in social psychological research: Conceptual, strategic, and statistical considerations. Journal of personality and social psychology, 51(6), 1173.

7. Bernerth, J. B., Armenakis, A. A., Feild, H. S., Giles, W. F., \& Walker, H. J. (2007). Leader-member social exchange (LMSX): Development and validation of a scale. Journal of Organizational Behavior: The International Journal of Industrial, Occupational and Organizational Psychology and Behavior, 28(8), 9791003.

8. Bonneville-Roussy, A., Lavigne, G. L., \& Vallerand, R. J. (2011). When passion leads to excellence: The case of musicians. Psychology of Music, 39(1), 123-138. 
9. Buch, R., Kuvaas, B., \& Dysvik, A. (2019). The role of other orientation in reactions to social and economic leader-member exchange relationships. Journal of Organizational Behavior, 40(3), 296-310.

10.Burke, R. J., Astakhova, M. N., \& Hang, H. (2015). Work passion through the lens of culture: Harmonious work passion, obsessive work passion, and work outcomes in Russia and China. Journal of Business and Psychology, 30(3), 457-471.

11.Byrne, B. M. (1994). Burnout: Testing for the validity, replication, and invariance of causal structure across elementary, intermediate, and secondary teachers. American Educational Research Journal, 31(3), 645-673.

12.Cannon, N. H., Herda, D. N., \& Puffer, T. M. (2019). Practitioner summary Big 4 Alumni's Attitudes and Behavior Toward their Former Firm. Current Issues in Auditing.

13.Chu, T.-H., \& Chiu, Y.-T. (2017). We are in the same boat: The effect of social interdependences on knowledge boundary spanning in interdisciplinary collaboration. Journal of Information Management, 24(3), 307-340.

14.Conejero, S., \& Etxebarria, I. (2007). The impact of the Madrid bombing on personal emotions, emotional atmosphere and emotional climate. Journal of social issues, 63(2), 273-287.

15.Cropanzano, R., Anthony, E. L., Daniels, S. R., \& Hall, A. V. (2017). Social exchange theory: A critical review with theoretical remedies. Academy of Management Annals, 11(1), 479-516.

16.Cropanzano, R., \& Mitchell, M. S. (2005). Social exchange theory: An interdisciplinary review. Journal of management, 31(6), 874-900.

17.Dulebohn, J. H., Bommer, W. H., Liden, R. C., Brouer, R. L., \& Ferris, G. R. (2012). A meta-analysis of antecedents and consequences of leader-member exchange: Integrating the past with an eye toward the future. Journal of management, 38(6), 1715-1759.

18.Eisenberger, R., Stinglhamber, F., Vandenberghe, C., Sucharski, I. L., \& Rhoades, L. (2002). Perceived supervisor support: Contributions to perceived organizational support and employee retention. Journal of Applied Psychology, 87(3), 565.

19.Ekawati, E., \& Tjahjono, H. K. (2019). The Influence of Prosedural Justice and Organizational Climate on Organizational Citizenship Behavior (OCB) With Employee Engagement as a Mediator. Account and Financial Management Journal, 4(01), 1847-1853.

20.Erdogan, B., \& Enders, J. (2007). Support from the top: Supervisors' perceived organizational support as a moderator of leader-member exchange to satisfaction and performance relationships. Journal of Applied Psychology, 92(2), 321.

21.Ericsson, K. A., Krampe, R. T., \& Tesch-Römer, C. (1993). The role of deliberate practice in the acquisition of expert performance. Psychological review, 100(3), 363.

22.Gaan, N., \& Mohanty, P. (2019). On Passion \& Sustainable Leadership: Personal \& Organizational Outcomes in India. Indian Journal of Industrial Relations, 54(3).

23.Graen, G. B., \& Uhl-Bien, M. (1995). Relationship-based approach to leadership: Development of leader-member exchange (LMX) theory of leadership over 25 years: Applying a multi-level multi-domain perspective. The leadership quarterly, 6(2), 219-247.

24.Huang, L.-C., Gao, M., \& Hsu, P.-F. (2019). Effects of Organizational Justice on Organizational Climate and Organizational Performance in Ecology Industry. Ekoloji, 28(107), 237-241.

25.Issac, G., Rajendran, C., \& Anantharaman, R. (2006). An instrument for the measurement of customer perceptions of quality management in the software industry: An empirical study in India. Software Quality Journal, 14(4), 291-308.

26.Kang, J. H., Matusik, J. G., Kim, T.-Y., \& Phillips, J. M. (2016). Interactive effects of multiple organizational climates on employee innovative behavior in entrepreneurial firms: A cross-level investigation. Journal of Business Venturing, 31(6), 628-642.

27.Kuvaas, B., \& Buch, R. (2018). Leader-member exchange relationships and follower outcomes: The mediating role of perceiving goals as invariable. Human Resource Management, 57(1), 235-248.

28.Landrum, H., Zhang, X., Prybutok, V., \& Peak, D. (2009). Measuring IS system service quality with SERVQUAL: Users' perceptions of relative importance of the five SERVPERF dimensions. Informing science, 12. 
29.Lapointe, É., Vandenberghe, C., Ayed, A. K. B., Schwarz, G., Tremblay, M., \& Chenevert, D. (2019). Social Comparisons, Self-Conceptions, and Attributions: Assessing the Self-Related Contingencies in LeaderMember Exchange Relationships. Journal of Business and Psychology, 1-22.

30.Litwin, G. H., \& Stringer, R. A. (1968). Motivation and organizational climate.

31.Martin, R., Guillaume, Y., Thomas, G., Lee, A., \& Epitropaki, O. (2016). Leader-member exchange (LMX) and performance: A meta-analytic review. Personnel Psychology, 69(1), 67-121.

32.Matta, F. K., \& Van Dyne, L. (2015). Leader-member exchange and performance: Where we are and where we go from here. The Oxford handbook of leader-member exchange, 157-174.

33.Mensah, L. D., Yamoah, J. O., \& Adaramola, M. S. (2019). Performance evaluation of a utility-scale grid-tied solar photovoltaic (PV) installation in Ghana. Energy for Sustainable Development, 48, 82-87.

34.Neal, A., Griffin, M. A., \& Hart, P. M. (2000). The impact of organizational climate on safety climate and individual behavior. Safety science, 34(1-3), 99-109.

35.Nunnally, J. (1978). Nunnally on reliability. Retrieved on June, 10, 2008.

36.Ölçer, F., \& Florescu, M. (2015). Mediating effect of job satisfaction in the relationship between psychological empowerment and job performance. Theoretical and Applied Economics, 22(3), 111-136.

37.Páez, D., Ruiz, J. I., Gailly, O., Kornblit, A. L., Wiesenfeld, E., \& Vidal, C. M. (1997). Clima emocional: su concepto y medición mediante una investigación transcultural. Revista de Psicología Social, 12(1), 79-98.

38.Peña Suárez, E., Muñiz Fernández, J., Campillo Álvarez, Á., Fonseca Pedrero, E., \& García Cueto, E. (2013). Assessing organizational climate: Psychometric properties of the CLIOR Scale. Psicothema.

39.Permarupan, P. Y., Saufi, R. A., Kasim, R. S. R., \& Balakrishnan, B. K. (2013). The impact of organizational climate on employee's work passion and organizational commitment. Procedia-Social and Behavioral Sciences, 107, 88-95.

40.Qiu, H., Haobin Ye, B., Hung, K., \& York, Q. Y. (2015). Exploring antecedents of employee turnover Intention-evidence of China's hotel industry. Journal of China Tourism Research, 11(1), 53-66.

41.Randhawa, G., \& Kaur, K. (2015). An empirical assessment of impact of organizational climate on organizational citizenship behaviour. Paradigm, 19(1), 65-78.

42.Rivai, R., Gani, M. U., \& Murfat, M. Z. (2019). Organizational Culture and Organizational Climate as a Determinant of Motivation and Teacher Performance. Advances in Social Sciences Research Journal, 6(2).

43.Saleem, M. A., Bhutta, Z. M., Nauman, M., \& Zahra, S. (2019). Enhancing performance and commitment through leadership and empowerment: An emerging economy perspective. International Journal of Bank Marketing, 37(1), 303-322.

44.Schneider, B., González-Romá, V., Ostroff, C., \& West, M. A. (2017). Organizational climate and culture: Reflections on the history of the constructs in the Journal of Applied Psychology. Journal of Applied Psychology, 102(3), 468.

45.Schulte-Holthaus, S. (2019). Passion and Performance in Entrepreneurial Contexts: An Interestbased Approach. The Journal of Entrepreneurship, 0971355719851895.

46.Suarez, C., Carroll, R. T., Burke, T. A., Christensen, J. R., Bestul, A. J., Sees, J. A., . . Kovar, D. R. (2015). Profilin regulates F-actin network homeostasis by favoring formin over Arp2/3 complex. Developmental cell, 32(1), 43-53.

47.Tweedie, D., Wild, D., Rhodes, C., \& Martinov-Bennie, N. (2019). How does performance management affect workers? Beyond human resource management and its critique. International Journal of Management Reviews, 21(1), 76-96.

48.Vallerand, R. J., Blanchard, C., Mageau, G. A., Koestner, R., Ratelle, C., Léonard, M., . . Marsolais, J. (2003). Les passions de l'ame: on obsessive and harmonious passion. Journal of personality and social psychology, 85(4), 756.

49.Vallerand, R. J., Houlfort, N., \& Fores, J. (2003). Passion at work. Emerging perspectives on values in organizations, 175-204.

50.Vallerand, R. J., Paquet, Y., Philippe, F. L., \& Charest, J. (2010). On the role of passion for work in burnout: A process model. Journal of personality, 78(1), 289-312.

51.Wayne, S. J., \& Green, S. A. (1993). The effects of leader-member exchange on employee citizenship and impression management behavior. Human Relations, 46(12), 1431-1440. 